\title{
Reactive Printing and Crease Resistance Finishing of Cotton Fabrics-Effects of Fixation Modes by $2^{2} \cdot 4^{1}$ Mixed Factorial Design
}

\author{
Fare ha Asim ${ }^{1, *}$, Muzzaffar Mahmood ${ }^{2}$ \\ ${ }^{1}$ Department of Textile En gineering, NED University of Engineering, Technology Karachi, Pakistan \\ ${ }^{2}$ Department of Mechanical En gin eering, NED University of Engin eering, Technology Karachi, Pakistan
}

\begin{abstract}
A single step fixation for reactive printing and crease resistance finishing of cotton fabric has been exp lored in this research work using an experimental design technique (DOE). $2^{2} \cdot 4^{1}$ mixed factorial design have been conducted to efficiently identify the active set of factors and their interaction. All of the three factors namelychroma, concentration of crease resistant and fixation conditions were found to be significant. The results further show that apart from the influence of individual factors, the said properties of cotton fabric are also reliant on the interaction effect of the significant factors. The influence of individual factors and their interactions on color yield (K/S) and Dry Crease Recovery Angle (DCRA) has been critically examined using software Design Expert 7.0.The results showed that combination of the Econtrol* process at $130^{\circ} \mathrm{C}$ without urea has been verified experimentally to be the best selection for the single step fixation of reactive printing and crease resistance finishing for the cotton fabric using the pad-dry-print-fix method. The uncertainty analyses for measurements shows that the predicted values are in good agreement with experimental data and are sufficiently accurate.
\end{abstract}

Keywords DOE, Econtrol, Reactive Printing, Crease Resistance Finishing, K/S, DCRA

\section{Introduction}

Modern textile processes have high demand for development of a combined application of crease resistance finishing and reactive printing. A number of experimental and numerical studies on simultaneous fixation of reactive dyeing and crease res is tance finis hing have become availab le in recent years. However, some studies have reported on combined application of reactive printing and crease resistance finishing that probably due to contradictory application and fixation conditions of both processes, it is difficult to develop an acceptable combination.

There are numerous factors that influence the printing process of cotton fabric with reactive dyes. A number of theoretical and experimental studies exist providing detailed information about the effect of process parameters and operating conditions [1-9]. Since the 1950s many researchers [10-15] have attempted to combine reactive dyeing and crease resistance finishing processes into one step to capture the potential time, energy, and other savings associated with the combined process.

Some research [16] was conducted on combining CR

* Corresponding author:

fareha@neduet.edu.pk (FarehaAsim)

Published online at http://journal.sapub.org/textile

Copyright (C) 2012 Scientific \& Academic Publishing. All Rights Reserved fin ishing and pigment printing. Such combined application of finish and print, may not be favourable due to the differential finish effects resulting from the localisation of paste to an area of print design on the treated substrate.In summary, most prior studies did not experimentally evaluate the single step fixation process of reactive printing and crease resistance finishing. To make this technology practical, a new approach needs to be developed that gives high dye fixation, excellent crease recovery in a one step process.

\section{Experimental}

\subsection{Materials}

\subsubsection{Fabric}

Commercially singed, desized, scoured, bleached and mercerized cotton fabric with satin weave structure, $40 \times 40 \mathrm{~s}$, 130 ends/inch $\times 73$ picks/inch, and an area density of approximately $136 \mathrm{~g} / \mathrm{m}^{2}$.

\subsubsection{Chemical and Colorants}

The Crease recovery finishing agent used was Arkofix NEC (Clariant), based on modified dimethyloldihydroxy ethylene urea. Magnesium chloride $\left(\mathrm{MgCl}_{2}\right)$ was used to catalyze the CR finishing, Solusoft MW (Silicon softener), 
Ceranine-L (An ionic Softener) and Imercol PCLF (Wetting Agent).

The reactive dye used was Drimarine Red P2B (Clariant), based on the MCT reactive group. Other chemicals used were commercially available thickener Lamitex HP (sodium alginate), sodium bicarbonate, urea, reduction inhibitor (RevatolS) and sodium hexametaphosphate as a sequestrant.

\subsection{Methods}

Print-finish paste manufacture

A concentration of $2.50-3.00 \% \mathrm{w} / \mathrm{w}(30 \mathrm{~g} / \mathrm{kg})$ of thickener Lamitex HP (to maintain the $60-65 \mathrm{dPa}$ viscosity range) was added to produce stock paste with continuous high speed stirring to the required volume of water. This was followed by the gradual addition of urea $200 \mathrm{~g} / \mathrm{kg}$, sodium bicarbonate $30 \mathrm{~g} / \mathrm{kg}$, Revatol $\mathrm{S} 10 \mathrm{~g} \mathrm{~m} / \mathrm{kg}$ and sodiu mhe xametaphosphate $5 \mathrm{~g} \mathrm{~m} / \mathrm{kg}$ with continuous stirring giving a final stock paste viscosity of $60-65 \mathrm{dPa}$. However, urea is not added in the stock paste manufactured for the experiments conducted using the Econtrol without urea method for fixation. The printing pastes of different concentrations were prepared with Drimarine Red P2B as outlined in Table 1. During stock and print paste preparation a vigorous high speed stirring for $10 \mathrm{~min}$ was required to obtain a homogenous paste after adding all reagents. The viscosities of all types of pastes were measured using a Brookfield Viscometer (Type LV). The CR finishing liquor was prepared by using Magnesium Chloride $25 \%$ of CR but not greater than $30 \mathrm{~g} / \mathrm{l}$, Solusoft MW 20g/l, Ceranine-L 20g/l and Imercol PCLF $1 \mathrm{~g} / 1$. The final finish bath was prepared with Arkofix NEC as outlined in Table 1.

Table 1. Factors and respect ive levels used in $2^{2} \cdot 4^{1}$ mixed fact orial design

\begin{tabular}{|c|c|c|c|c|c|}
\hline \multicolumn{2}{|c|}{ Factor Name } & \multicolumn{3}{|c|}{ Levels } \\
\hline A & Chroma & \multicolumn{2}{|c|}{$1 \%$} & \multicolumn{2}{c|}{$3 \%$} \\
\hline B & $\begin{array}{c}\text { Conc. Of } \\
\text { Crease } \\
\text { Resistant }\end{array}$ & \multicolumn{2}{|c|}{$100 \mathrm{~g} / 1$} & \multicolumn{2}{c|}{$200 \mathrm{~g} / 1$} \\
\hline C & $\begin{array}{c}\text { Fixation } \\
\text { Conditions }\end{array}$ & $\begin{array}{c}\text { Saturated } \\
\text { Steam } \\
102^{\circ} \mathrm{C}-8 \mathrm{~min}\end{array}$ & $\begin{array}{c}\text { Hot Air } \\
150^{\circ} \mathrm{C}-5 \mathrm{~min}\end{array}$ & $\begin{array}{c}\text { Econtrol } \\
\text { Urea } \\
0 \mathrm{~g} / \mathrm{kg}\end{array}$ & $\begin{array}{c}\text { Econtrol } \\
\text { Urea } \\
50 \mathrm{~g} / \mathrm{kg}\end{array}$ \\
\hline
\end{tabular}

Print-finish Procedure

The CPF process was carried out as follows: In the first stage the fabric was immersed in an aqueous solution of CR fin ish liquor, and then squeezed to obtain a $70 \%$ wet pickup. The wet fabric was then dried at $100^{\circ} \mathrm{C}$ for $1 \mathrm{~min}$. In the second stage the treated fabric was printed by the lab scale Rotary Printing machine (Zimmer). The printed fabric going to be fixed though steaming and curing process was again dried at $100^{\circ} \mathrm{C}$ for $1 \mathrm{~min}$. However, the printed fabrics fixed through the Econtrol process was not dried. In the third stage, the print-fin ish fabric was fixed. The preparation of fin ish bath, printing recipe and fixation method and temperature were employed in accordance with the experimental design arrangement as stated in Table 1 and 2. The fixed samples were finally washed in $1 \mathrm{~g} / 1$ non-ionic detergent until all unreacted dyes and chemicals were removed from the fabric surface.

\section{Evaluation of Fabric Properties}

Color yield measurement

The printed fabrics were conditioned (at temperature $25 \pm 1$ $\mathrm{C}$ and relative humidity $65 \pm 1 \%$ ) before color yield measurement with a Tex-Flash spectrophotometer. The condition for measurement was set under specular excluded with large aperture. The fabric was folded twice to ensure opacity.

The color yield ( $\mathrm{k} / \mathrm{s}$ value) was calculated for wavelengths $400-700 \mathrm{~nm}$ at $20 \mathrm{~nm}$ intervals within the visible spectrum. The $\mathrm{k} / \mathrm{s}$ was calculated according to Eqn 1:

$$
\mathrm{K} / \mathrm{S}=(1-\mathrm{R})^{2} / 2 \mathrm{R}
$$

Where, kis the absorption coefficient, $\mathrm{s}$ is the scattering coefficient and $\mathrm{R}$ is the reflectance of the colored samples. The higher the $\mathrm{k} / \mathrm{s}$ value is, the greater the color yie ld and dye uptake.

\section{Evaluation of Crease Recovery Angle}

The print-finish fabrics were conditioned (at temperature $25 \pm 1 \mathrm{C}$ and relative humidity $65 \pm 1 \%$ ) before the measurement of easy-care properties imparted by the CR fin ish. The dry crease recovery angle (DCRA) of the fabric was measured using AATCC test method 66-1990, using Shirley Crease recovery tester. The wider the DCRA is, the higher the crease recovery.

\section{Experiment Design}

$2^{2} .4^{1}$ mixed factorial design was used to explore the effect of different factors namely: (i) chroma, (ii) concentration of crease resistant, (iii) fixation Conditions on combined reactive printing and crease resistance finishing.A $2^{2} .4^{1}$ mixed factorial design of 16 trials with two repetitions were run according to the design matrix shown in Table 2 . The experiments were performed in random order. The results were analyzedusing software Design Expert 7.0. The responses investigated were the colour yield and dry crease recovery angle.The details of the experimental design arrangement are shown in Tables 1 and 2.

\section{Results and Discussion}

The results from the experiment suggest that all of three factors and two interactions were significant. The significant interactions are chroma and fixation conditions and concentration of crease resistant and fixation conditions. The experimental results, ANOVA for K/S and DCRA are shown in Table 2, 3 and 4 respectively. 
Fareha Asim et al:: Reactive Printing and Crease Resistance Finishing of Cotton Fabrics-Effects of

Fixation Modes by $2^{2} \cdot 4^{1}$ Mixed Factorial Design

Table 2. $2^{2} \cdot 4^{1}$ mixed factorial design matrix (Run Order)

\begin{tabular}{|c|c|c|c|c|c|}
\hline Run & $\begin{array}{c}\text { A } \\
\text { (Chroma) }\end{array}$ & $\begin{array}{c}\mathrm{B} \\
\text { (Concentration Of CR) }\end{array}$ & $\begin{array}{c}\mathrm{C} \\
\text { (Fixation Condition) }\end{array}$ & $\mathrm{K} / \mathrm{S}$ & DCRA \\
\hline 1 & Level 2 & Level 2 & Level 3 & 5.6 & 129 \\
\hline 2 & Level 1 & Level 1 & Levell & 2.5 & 70 \\
\hline 3 & level 1 & Level 2 & Level 2 & 1.1 & 107 \\
\hline 4 & Level 1 & Level 2 & Level4 & 1.9 & 120 \\
\hline 5 & Level 1 & Level 1 & Level 3 & 3.9 & 90 \\
\hline 6 & Level 2 & Level 1 & Level 3 & 6 & 107 \\
\hline 7 & Level 2 & Level 2 & Level 2 & 3.3 & 88 \\
\hline 8 & Level 1 & Level 2 & Level3 & 3.5 & 120 \\
\hline 9 & Level 1 & Level1 & Level 4 & 2.1 & 88 \\
\hline 10 & Level 2 & Level 1 & Level 2 & 3.8 & 97 \\
\hline 11 & Level 2 & Level 1 & Level 1 & 5 & 85 \\
\hline 12 & Level 1 & Level 1 & Level 2 & 1.2 & 96 \\
\hline 13 & Level 2 & Level2 & Level 1 & 4.5 & 97 \\
\hline 14 & Level 2 & Level 1 & Level 4 & 3.1 & 88 \\
\hline 15 & Level 1 & Level 2 & Level 1 & 1.8 & 88 \\
\hline 16 & Level 2 & Level 2 & Level 4 & 2.6 & 115 \\
\hline
\end{tabular}

Table 3. ANOVA for response $\mathrm{K} / \mathrm{S}$ of screening experiment Set -03

\begin{tabular}{|cccccc|}
\hline Source & Sum of Squares & $\mathrm{df}$ & Mean Square & F -Value & $\mathrm{p}$-Value \\
Model & 33.52 & 12 & 2.79 & 147.35 & 0.0008 \\
A- Chroma & 15.80 & 1 & 15.80 & 833.44 & $<0.0001$ \\
B- Conc. Of CR & 0.68 & 1 & 0.68 & 35.90 & 0.0093 \\
C-Fixation Condition & 15.12 & 3 & 5.04 & 265.88 & 0.0004 \\
AB & 0.016 & 1 & 0.016 & 0.82 & 0.4309 \\
AC & 1.85 & 3 & 0.62 & 32.56 & 0.0087 \\
BC & 0.052 & 3 & 0.017 & 0.91 & 0.5293 \\
Residual & 0.057 & 3 & 0.019 & & 0.9983 \\
Cor Total & 33.58 & 15 & & & 0.9915 \\
Std. Dev. & & & R-Squared & & \\
Mean & 0.14 & & Adj R-Squared & \\
\hline
\end{tabular}

Table 4. ANOVA for response DCRA of screening experiment Set-03

\begin{tabular}{|cccccc|}
\hline Source & Sum of Squares & $\mathrm{df}$ & Mean Square & F -Value & $\mathrm{p}$-Value \\
Model & 3748.75 & 12 & 312.40 & 25.90 & 0.0107 \\
A- Chroma & 45.56 & 1 & 45.56 & 3.78 & 0.1472 \\
B- Conc. Of CR & 1278.06 & 1 & 1278.06 & 105.95 & 0.0020 \\
C-Fixation Condition & 1481.19 & 3 & 493.73 & 40.93 & 0.0062 \\
AB & 95.06 & 1 & 95.06 & 7.88 & 0.0674 \\
AC & 354.69 & 3 & 118.23 & 9.80 & 0.0465 \\
BC & 494.19 & 3 & 164.73 & 13.66 & 0.0296 \\
Residual & 36.19 & 3 & 12.06 & & 0.9904 \\
Cor Total & 3784.94 & 15 & & & 0.9522 \\
Std. Dev. & & & R-Squared & \\
Mean & 3.47 & & Adj R-Squared & \\
\hline
\end{tabular}




\subsection{Assess ment of the Significant Interactions in Combo Process}

Influence of Chroma and fixation conditions

The interaction of chroma and fixation condition found to be significant for both the responses $\mathrm{K} / \mathrm{S}$ and DCRA. The interaction plots of Figure 1and Figure 2clearly illustrate that the Econtrol without urea process give highest $\mathrm{K} / \mathrm{S}$ and
DCRA as compared any other fixation method.

Increasing the chroma results in a radical increment of $\mathrm{K} / \mathrm{S}$ (Figure 2) shows that by increasing the concentration of dye, DCRA also increases in the case of Econtrol without urea and steaming process of fixation. This is highly probable when covalent bonding of reactive dye results in entrapping of crease resistant in the fiber system.

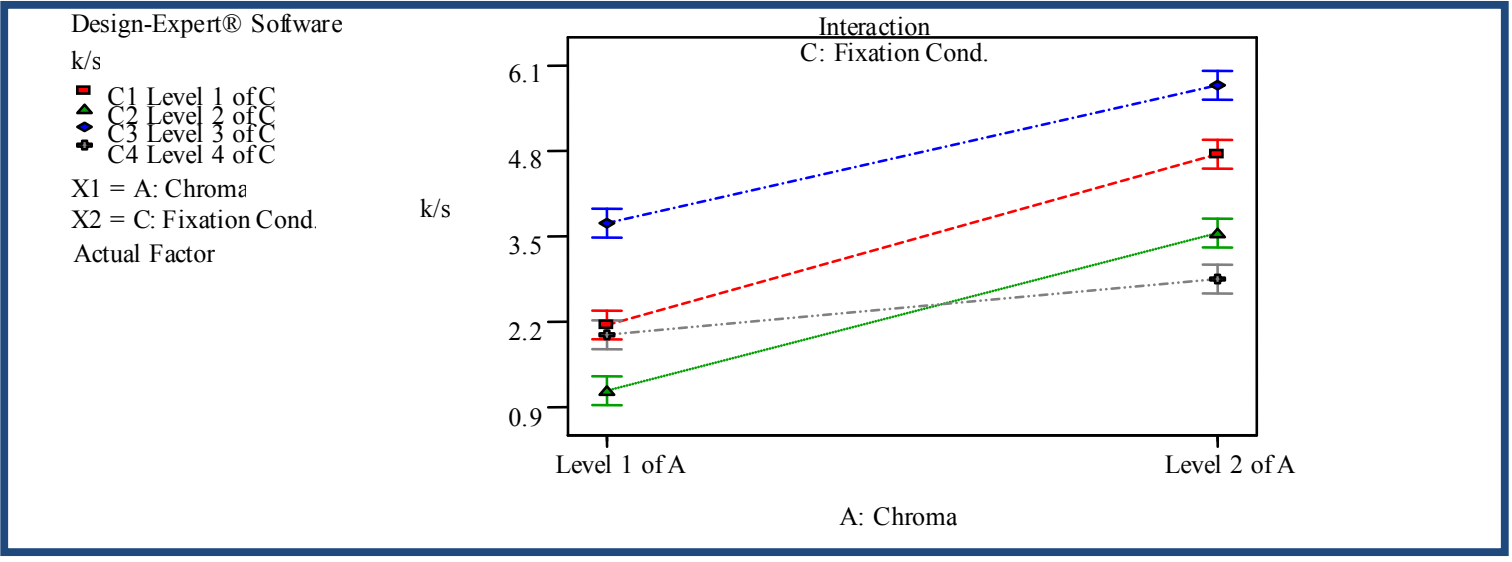

Figure 1. Interaction plot of chroma and fixation condition with respect to $\mathrm{K} / \mathrm{S}$

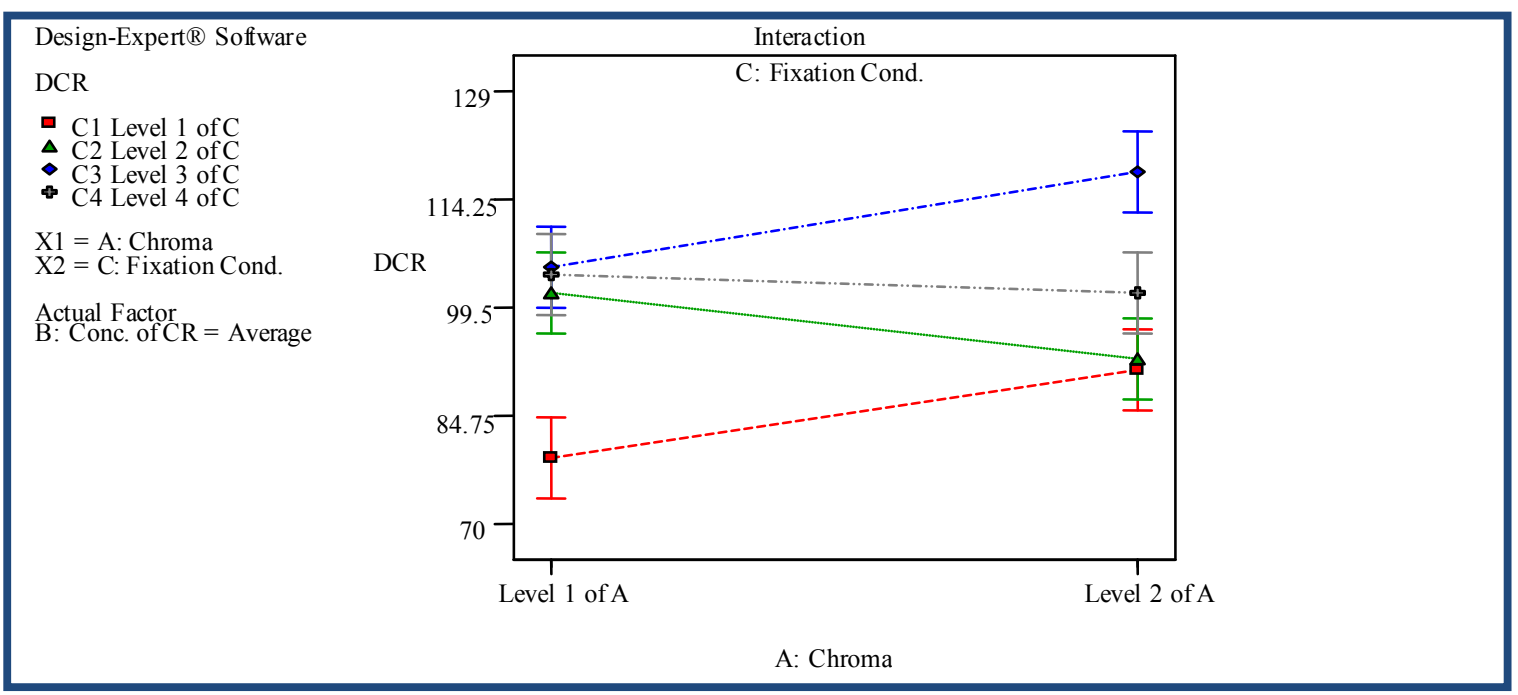

Figure 2. Interaction plot of chroma and fixation condition with respect to DCRA
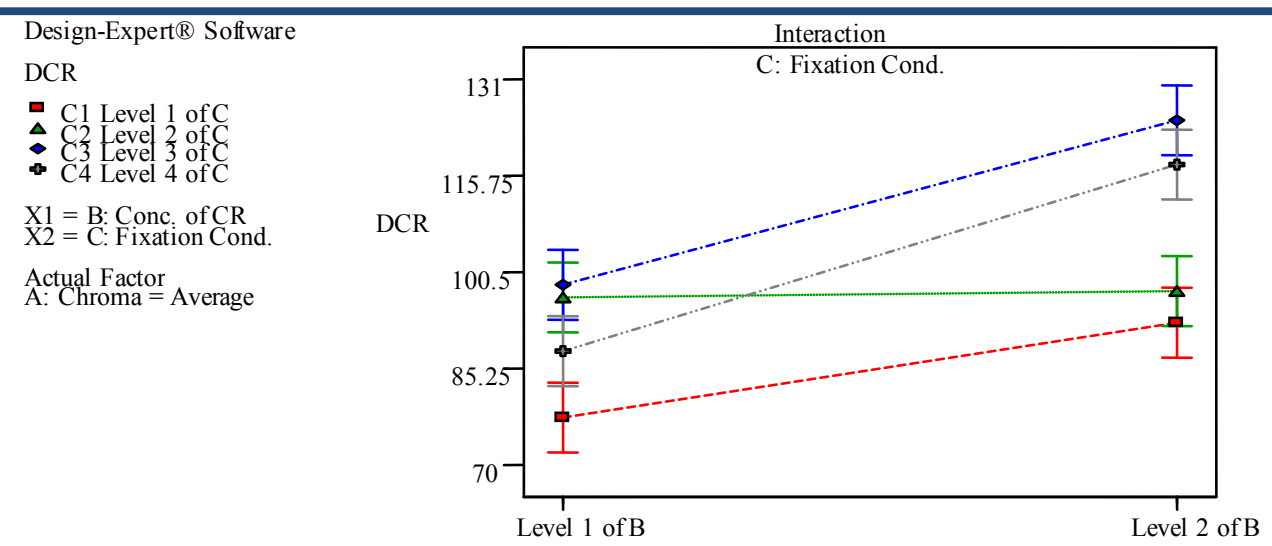

B: Conc. of CR

Figure 3. Interaction plot of concentrat ion of CR and fixat ion condition with respect to DCRA 
Influence of concentration of CR and fixation conditions

The interaction of the concentration of CR and fixation conditions was found to be significant for DCRA. As was observed earlier, the Econtrol without urea process yields the best results. Figure 3 illustrates with the increase in concentration of crease resistant, the increment in DCRA is highest in the Econtrol process as compared to other fixation methods.

\subsection{Ass ess ment of the Significant Factors}

Influence of chroma

The main factor plot of chroma is shownin Figure 4 which reveals that as chroma increases, $\mathrm{K} / \mathrm{S}$ increases while other factors are kept at average values.

Influence of concentration of CR

The main factor plots of concentration of CR are shown in Figure 5 and 6 . Figure 5 showed that as the concentration of $\mathrm{CR}$ increases, $\mathrm{K} / \mathrm{S}$ decreases keeping other factors at average values. However, Figure 6 illustrates that as the concentration of CR increases, DCRA increases keeping other factors at average values.

Influence of fixation condition

The main factor plots of fixation conditions are shown in Figure 7 and 8 . The plots of fixation condition showed that the final colour yield and DCRA attained the maximum value for the Econtrol without urea process.

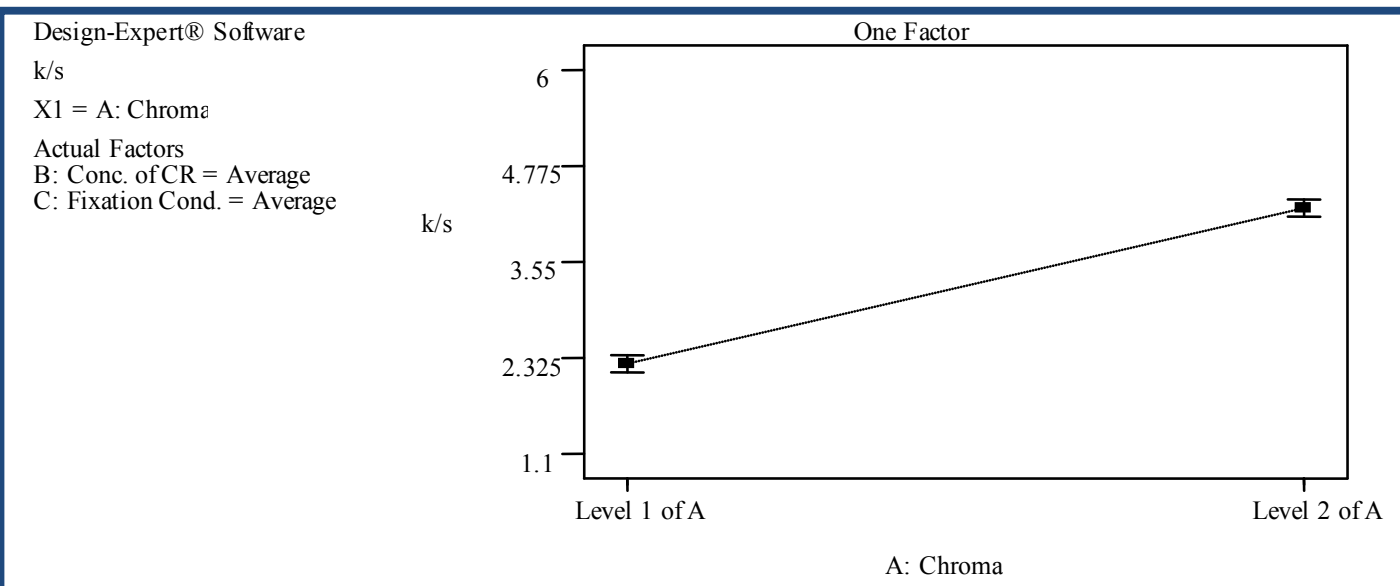

Figure 4. Effect of chroma on $\mathrm{K} / \mathrm{S}$

Design-Expert ${ }^{\circledR}$ Software

$\mathrm{k} / \mathrm{s}$

$\mathrm{X} 1=\mathrm{B}$ : Conc. of $\mathrm{CR}$

Actual Factors

A: Chroma $=$ Average
C: Fixation Cond. $=$ Average

$\mathrm{k} / \mathrm{s}$

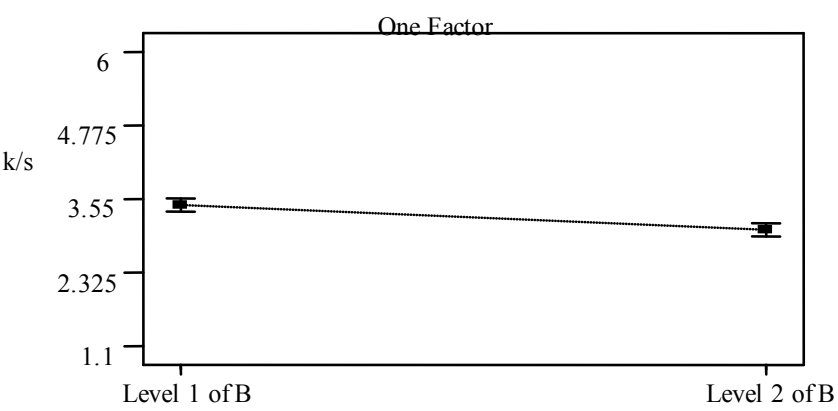

B: Conc. of $\mathrm{CR}$

Figure 5. Effect of concentration of $\mathrm{CR}$ on $\mathrm{K} / \mathrm{S}$

Design-Expert ${ }^{\circledR}$ Software

DCR

$\mathrm{X} 1=\mathrm{B}$ : Conc. of $\mathrm{CR}$

Actual Factors

C: Fixation Cond. $=$ Average

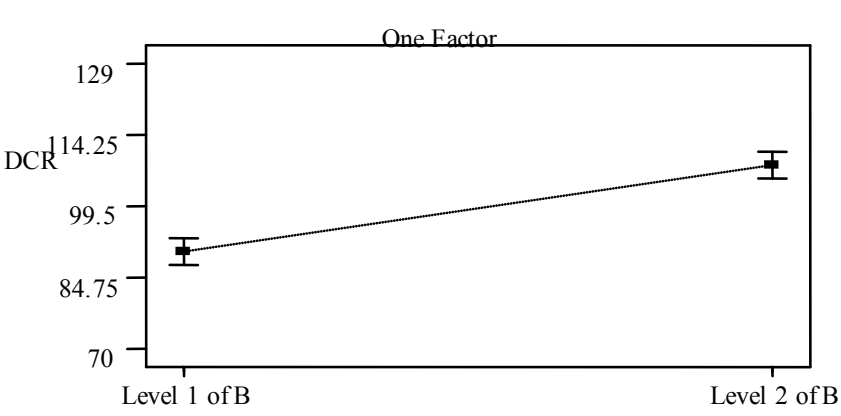

B: Conc. of CR

Figure 6. Effect of concentration of CR on DCRA 


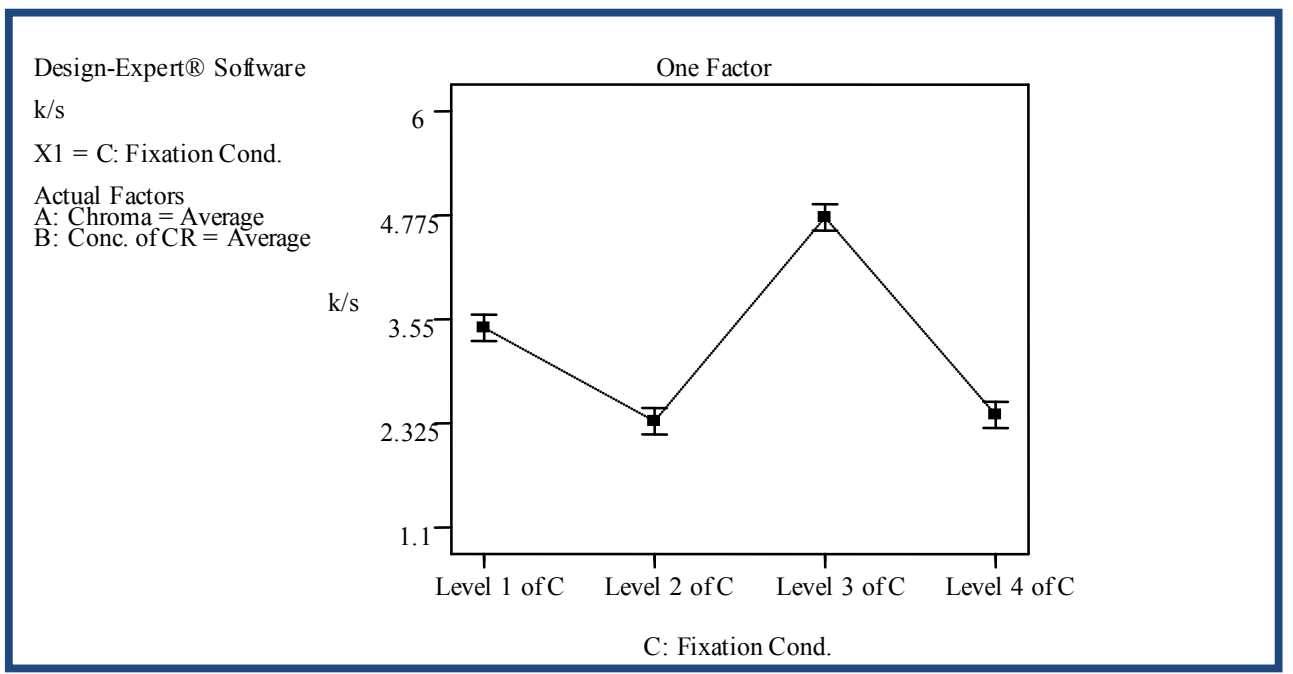

Figure 7. Effect of fixation conditions on $\mathrm{K} / \mathrm{S}$

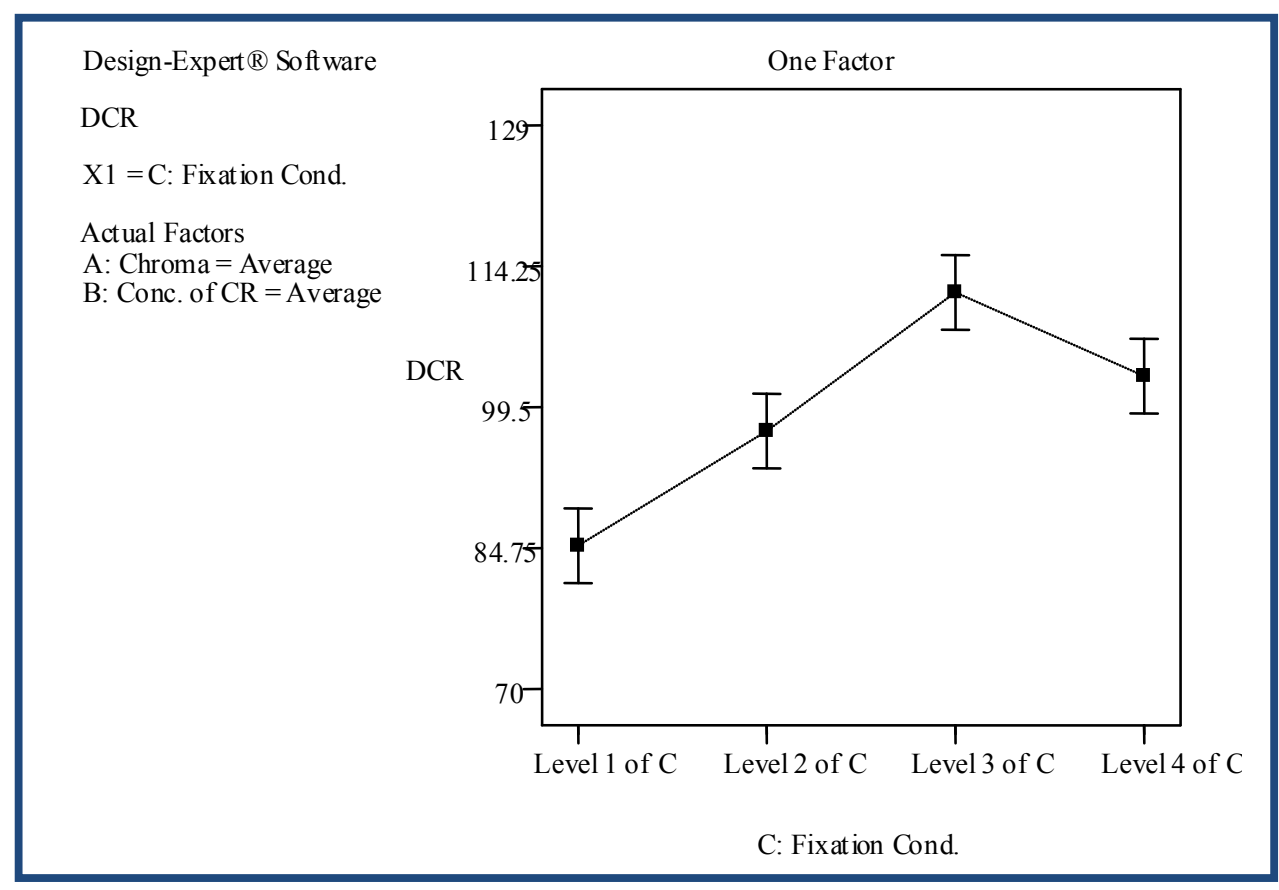

Figure 8. Effect of fixation conditions on DCRA

\section{Conclusions}

The statistical analysis of the influential factors revealed the interaction effect of each factor on the response variables of reactive printing and crease resistance finishing process. For both the responses K/S and DCRA, the Econtrol without urea process yields the most favorable results as compared to any other fixation method for the CPF process.

The high values of coefficient of determination as indicated in Table 3 and 4 implied that the models effectively explained the combined process. The interaction graphs forchroma\& fixation conditions and concentration of CR \& fixation conditionsdemonstrate that the Econtrol method of fixation at $130^{\circ} \mathrm{C}$ using the pad-dry-print-fix-wash method provides an efficient system for imparting single step fixation of reactive printing and crease resistance finishing.

The graphical analys es of factors revealed the significant effect of chroma, concentration of crease resistant, fixation condition on the comnbined process. Based on the experimental design study, it has been further confirmed that each factor had an interaction effect with other factors. Furthermore, the models have been tested for adequacy and found that the assumption of norma lity and independency are not violated. $\mathrm{R}^{2}$ values were very high, suggesting that models accounted for most of the variability.

\section{ACKNOWLEDGEMENTS}

The authors acknowledge the permission given by Clariant Pakistan Ltd, for carrying out the necessary experimental work 


\section{REFERENCES}

[1] Y.H. El Hamaky, S. Tawfeek, D. F. Ibrahim, D. Maamoun, S. Gaber, "Printing Cotton Fabrics with Reactive Dyes of High Reactivity from an Acidic Printing Paste", Coloration Technology, 123(6), 365-373 (2007)

[2] N. S. E. Ahmed, Y. A. Yourself, R. M. El-Shishtawy, A. A Mousa, "Urea/Alkali Free Printing of Cotton with Reactive Dyes", Coloration Technology, 122(6), 324-328 (2006)

[3] Y. Yang, V. Naarani, "Effect of Steaming Conditions on Colour and Consistency of Ink-Jet Printed Cotton Using Reactive Dyes", Coloration Technology, 120(3), 127-131 (2004)

[4] C. W. M. Yuen, S. K. A. Ku, P. S. R. Choi, C. W. Kan, "Study of the Factors Influencing Colour Yield of an Inkjet-Printed Cotton Fabric", Coloration Technology, 120(6), 320-325 (2004)

[5] V. Vassileva, E. Valcheva, Z. Zheleva, "The Kinetic Model of Reactive

[6] D. Heywood, "Easy-Care Finishing of Cellulosics", Society of Dyers and Colourists 337-338 (2003)

[7] Y. Can, M. Akaydin, Y. Turhan, E. Ay, "Effect of Wrinkle Resistance Finish on Cotton Fabric Properties", Indian Journal of Fibre \& Textile Research, 34, 183-186 (2009)

[8] S. M. Mortazavi, P. E. Boukany, “Application of Mixtures of Resin Finishing to Achieve some Physical Properties on Interlining Cotton Fabrics: I-Effect of Stiffening and Cross-Linking Agents", Iranian Polymer Journal, 13(3), 213-218 (2004)
[9] N. F. Getchell, N. R.S. Hollies, "Two Component Wet Fixation Process for Imparting Durable Press to Cellulose Containing Materials", US Patent 3,472,606, November (1965)

[10] A. Chakraborty, C. Dutta, "Kinematics of Concurrent Dyeing and Finishing-A Critical Study", Proceed ings of International Conference on Energy and Environment, March (2009)

[11] H. M. Choi, M. Srinivasan, N. M. Morris, "Single-Step Dyeing and Finishing Treatment of Cotton with 1, 2, 3, 4-Butanetetracarboxylic Acid", Journal of Applied Polymer Science, 54(13), 2107-2118 (1994)

[12] Y. Dong, J. Wang, P. Liu, "Dyeing and Finishing of Cotton fabric in a Single Bath with Reactive Dyes and Citric Acid", Coloration Technology, 117(5), 262-265 (2001)

[13] B. Herman, B. Arthur, A. Hans, "Process for the Dy eing or Printing and Simultaneous Finishing of Cellu lose Materials", US Patent 3983588, May (1976)

[14] M. Montazer, M. G. Afjeh, "Simultaneous X-linking and Antimicrobial Finishing of Cotton Fabric", Journal of Applied Polymer Science, 103(1), 178-185 (2007)

[15] M. M. G. Fouda, A. El Shafei, S. Sharaf, A. Hebeish, "Microwave Curing for Producing Cotton Fabrics with Easy Care and Antibacterial Properties", Carbohydrate Polymers, 77(3), 651-655 (2009)

[16] F. Uddin, Mike Lomas, "Combined Crease Recovery Finishing and Pigment Printing", Coloration Technology, 121(3), 158-163 (2005) 